\title{
The efficacy of transnasal palatal transillumination for the diagnosis of submucous cleft palate
}

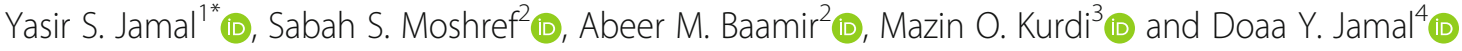

\begin{abstract}
Background: Submucous cleft palate (SMCP) is a congenital abnormality with various clinical and anatomical features. Submucous cleft pathologies may be unrecognized during routine examinations. Current diagnostic techniques are constrained and unrevealing in presurgical patients. This prospective study aimed to evaluate transnasal palatal transillumination technique in diagnosis of SMCP at our institute hospital, during period from 2005-2020.
\end{abstract}

Patients and methods: Twenty-one cases with SMCP were recruited with age range from 2-60 months. Transnasal palatal transillumination with controllable light intensity endoscope used to evaluate SMCP and cases were photo and video recorded.

Results: In this study, 21 cases (13 males and 8 females) with SMCP were detected or confirmed by intranasal transnasal palatal transillumination. Frequency of SMCP patients at our institute was 3.39\%. All patients presented with symptomatic complaints at diagnosis time, apart from 5 patients (23.8\%) were diagnosed during cleft lip repair operations. Presenting symptoms were hypernasality (23.8\%), delayed speech (23.8\%), perforated palate with nasal escape of milk and food (14.3\%), feeding difficulties (14.3\%), and otitis media (4.8\%). During intra-oral examination, all cases had a bifid uvula accompanied SMCP. Submucous cleft palate appeared as thin palate with central lucency. According to operative findings, operations done for repair were mostly two long palatal flaps $(n=13$, 61.9\%), von Langenbeck $(n=5,23.8 \%)$, simple repair with lateral release incisions ( $n=2,9.6 \%)$, and simple repair without lateral release incision $(n=1,4.8 \%)$.

Conclusions: Intraoperative assessment of submucous cleft palate with transnasal palatal transillumination is easy and cheap method to avoid missing cases of SMCP.

Keywords: Cleft palate, Diagnosis, Surgical repair, Transnasal palatal transillumination

\section{Background}

Cleft palate is one of the congenital anomalies usually diagnosed in neonatal evaluation. The most minor form of cleft palate is submucous cleft palate (SMCP). The palate appears clinically intact, but there are both bony and muscular deficits. It was first described by Calnan in 1954 as a triad "Calnan's triad" of bifid uvula, muscular

\footnotetext{
* Correspondence: Prof.yasir.jamal.2020@gmail.com

${ }^{1}$ Pediatric and Plastic Surgery, Faculty of Medicine, King Abdulaziz University, P.O. Box 80215, Jeddah 21589, Saudi Arabia

Full list of author information is available at the end of the article
}

diathesis, and hard palate posterior border notch [1]. Subsequent to Calnan's, it was clear that there were some anatomic differences among the disease. In approximately $50 \%$ of cases, all three classic characteristics appeared, while in about $30-40 \%$ only two of them were present [2]. In some cases, there were absent intraoral clinical findings; meanwhile, diastasis of muscle was found in surgery or imaging. The term "occult SMCP", was suggested by Kaplan [3] to distinguish these cases, which are about $10-20 \%$ of SMCP phenotype [4]. The occult submucous cleft palate includes abnormal velar

\section{Springer Open}

(๑) The Author(s). 2021 Open Access This article is licensed under a Creative Commons Attribution 4.0 International License, which permits use, sharing, adaptation, distribution and reproduction in any medium or format, as long as you give appropriate credit to the original author(s) and the source, provide a link to the Creative Commons licence, and indicate if changes were made. The images or other third party material in this article are included in the article's Creative Commons licence, unless indicated otherwise in a credit line to the material. If material is not included in the article's Creative Commons licence and your intended use is not permitted by statutory regulation or exceeds the permitted use, you will need to obtain permission directly from the copyright holder. To view a copy of this licence, visit http://creativecommons.org/licenses/by/4.0/. 
musculature, described both as decreased musculus uvulae bulk and abnormal musculus levator veli palatine insertion. Defect in musculus uvulae had been inferred by endoscopy and musculus levator veli palatini abnormality inferred at surgical dissection. SMCP can found as a separate disease, or as one of syndromes characteristics, as velo-cardio-facial syndrome. There is also high SMCP prevalence with isolated cleft lip [5].

SMCP clinical diagnosis is difficult and is diagnosed at later stage when children are complaining of speech abnormalities at school age. Symptoms can differ depending on child age. In babies, nasal regurgitation and /or feeding difficulties are frequent. As child getting older in age they complain recurrent ear defects as hearing disorders and frequent otitis media. Speech and language abnormalities become more apparent later and caused by abnormal insertion and positioning of palate muscles. The importance of SMCP finding in children is to make certain suitable treatment at early stage before irreversible speech difficulties [6]. Baek et al. showed that speech outcomes following surgical intervention are best prior to 5.5 years old, pointing necessity for early diagnosis and treatment [7]. SMCP may be recognized by MRI or nasopharyngoscopy, but these are hard to make prior 2 years old. A diagnostic delay have long-term results on speech development [5].

In this prospective study, the authors describe their experience in transnasal palatal transillumination as an easy method for SMCP detection, illustrating its facile utilization in preoperative case setup, with surgical outcome and to find out frequency of SMCP cases that were diagnosed and managed at hospital, during the 15year period from 2005 to 2020 .

\section{Methods}

In this prospective hospital-based study, evaluation of patients presented to our institute hospital with symptoms consistent with SMCP was made.

\section{Inclusion criteria}

All cases diagnosis as SMCP, confirmed by visual inspection and palate palpation as part of intra-oral examination were included.

\section{Exclusion criteria}

Patients with syndromes or comorbidity with SMCP were excluded.

During the study period (2005 till 2020), 21 cases were diagnosed using transnasal palatal transillumination of palate with nasoscope of controlled intensity light source as a simple method to identify membranous palate intraoperatively. This study was done according to latest version of Declaration of Helsinki and written informed consent was obtained from a parent or legal guardian of participants under 16 years old.

Transillumination of SMCP utilizing nasoscope is a simple diagnostic method that can be incorporated into preoperative evaluation. As part of assessing patients who had SMCP symptoms or undergoing cleft lip repair with bifid uvula, nasoscope was usually utilized to evaluate oropharynx, velum, and hypopharynx. The same scope could be utilized to refine detection of occult submucous cleft palate via palatal transillumination. This technique was done with general anesthesia as it was unpleasant particularly with none cooperative age. After scope introduction via nose and endoscopic inspection of velum, scope lighted distal end throws adjusted intensity light all over the palate from nasal side. When the scope is thus placed, the doctor was then capable to see the palate transilluminated lucent part via patient's open mouth. Normal palate appeared thick with equal transillumination, with muscular tissue found on all parts of velum midline that permit transmission of only little light. In contrast, membranous part including defective bony part of palate when transillumination showed a central lucency with absence of midline submucosal structures, and musculature that did not cross palate middle. This transilluminated palate characteristic, mainly if accompanied by endoscopic presence of midline convexity or flattening of superior velum makes seagull sign, must powerfully leads to diagnosis of submucous cleft. Palatal transillumination was very helpful in identification of the extent of membranous part and its width and the involvement of soft or hard palate or both in the defect. Upon submucous palate diagnosis, surgical intervention must be planned to prevent occurrence of velopharyngeal insufficiency (VPI) with its consequences in these patients.

According to the operative findings repair operation technique was either by two long palatal flaps, von Langenbeck technique or simple central closure of cleft palate with or without lateral release incisions. After intersection of palatal, oral, and nasal mucosa at membranous part with stressing to keep the nasal mucosa intact with the exception of the part of mucosa of uvula and at the site of oronasal fistula (when present). All patients were followed-up on a regular basis (1 week, 4 weeks, 6 weeks, and 3 months) postoperative for evaluation of palate proper healing.

\section{Statistical analysis}

The values were presented as mean, median, minimum, and maximum or number (\%) as appropriate and were analyses by IBM SPSS Statistics for Windows, version 23 (IBM SPSS, IBM Corp., Armonk, N.Y., USA). 


\section{Results}

At our institute during period from 2005 to 2020, total number of patients with cleft palate and cleft lip and palate were 620 cases including 21 with membranous palate defect. The frequency of patients with submucous cleft palate in our institute was $3.39 \%$. Patients' age ranges from 2 to 60 months. They were $13(61.9 \%)$ males and 8 (38.1\%) females. All patients with SMCP presented symptomatic complaints at diagnosis time; apart of 5 patients $(23.8 \%)$ were diagnosed during cleft lip repair operation. The most common presentations were hypernasality $(n=5,23.8 \%)$, delayed or abnormal speech $(n=5,23.8 \%)$, followed by perforated palate with nasal escape of milk and food ( $n=3,14.3 \%)$, feeding difficulties $(n=3,14.3 \%)$, and otitis media $(n=1,4.8 \%)$. During intra-oral examination, $100 \%$ of patients had a bifid uvula, which was associated with SMCP. The operative repair was done with different techniques based upon operative finding and extended of the defects with very satisfactory outcome in all patients $(n=21)$, three patients were repaired with simple closure of the cleft, without lateral release incision in one (4.8\%) (Fig. 1) and the other two (9.6\%) with lateral release incision (Fig. 2), but the repair was mostly done with two long palatal flaps technique ( $n=13,61.9 \%)$ (Fig. 3 ) and von Langenbeck technique ( $n=5,23.8 \%$ ) (Fig. 4). Transillumination finding help in determining repair technique used in
SMCP, according to extent of defective membranous part particularly the width of membranous part and involvement of bony palate where the surgeons need to use technique with sufficient mobilization of palatal flaps to close wide membranous defect to avoid dehiscence or fistula development. No post-repair fistula or dehiscence has occurred in any of the included patients (Table 1; Figs. 1, 2, 3, and 4).

\section{Discussion}

Submucous cleft palate is rare developmental anomalies which usually detected later after patient complains of VPI symptoms. Submucous cleft palate prevalence ranged $0.02-0.08 \%$ and is manifested by Calnan triad. On the other hand, occult submucous cleft palate did not have all signs while still have abnormal velum function and defect median muscle fusion [3]. Occult submucous cleft poverty visible signs of abnormalities, so it is hard to detected and is always diagnosed only when cases come with VPI manifestations of speech or feeding abnormalities [8].

In this study, during the 15-year period (2005-2020), 21 patients were managed with SMCP detected by transnasal palatal transillumination; mean patients' age was 18.95 months with age range from 2 to 60 months. In Northern Ireland, Martin et al. [9] made a retrospective review of SMCP children. They reported an elevated in
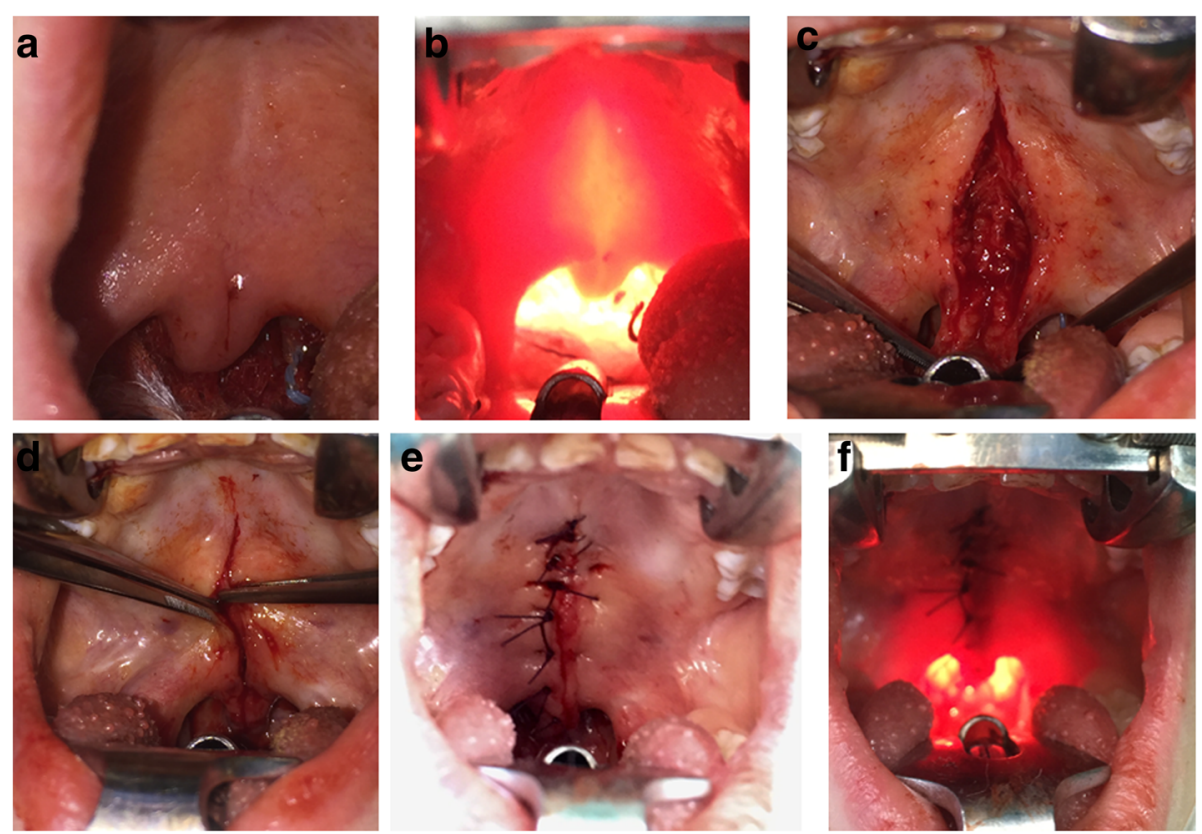

Fig. 1 a Transoral view of bifid uvula and zona pellucida (transparent). b Transnasal transillumination of palate showing bifid uvula and membranous part of palate extending to bony part. c Transoral dissection of central part of palate (intersection of palatal and nasal mucosa) with preservation of nasal mucosa showing muscular part on both side of membranous palate. $\mathbf{d}$ Approximation of palate muscle (levator palatini). e Repair of the palatal muscles and mucoperiosteal flaps on the oral side with 3-0 vicryl (simple repair without lateral release incisions). f Post-repair transnasal transillumination of palate 

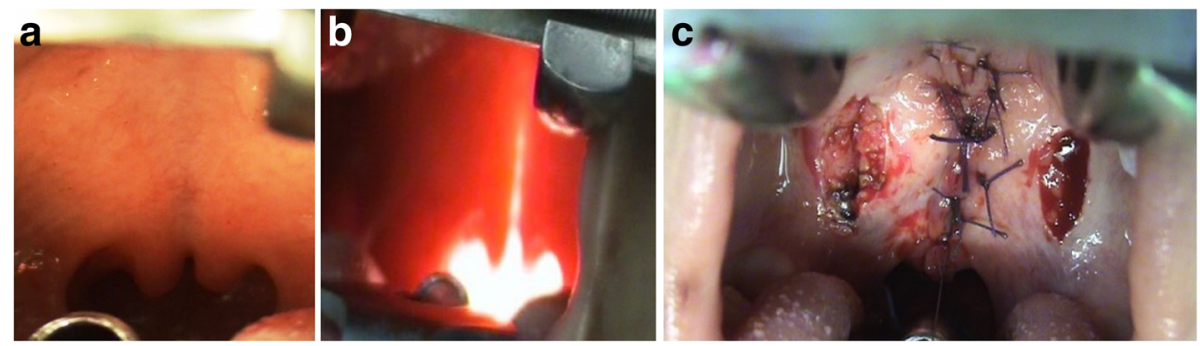

Fig. 2 a Transoral view of bifid uvula and zona pellucida. b Transnasal transillumination of palate showing bifid uvula and membranous part of palate. c Repair of palatal muscles and mucoperiosteal flaps on oral side with 3-0 vicryl (simple repair with lateral release incisions)

SMCP cases' numbers over 15-year period, from 6 cases between 1988 and 1995 to 25 cases between 2003 and 2010. The average age for primary palate reconstruction in earlier cohort was 6 years which decreased to 5.2 years in more recent cohort. These results highlighting those SMCP children in Northern Ireland were diagnosed at late age, when speech problems hindered their progress during early school years.
The frequency of patients with submucous cleft palate in our institute hospital was $3.39 \%$. The incidence of submucous clefts is roughly 1 in 1200 to 2000 [10]; however, this is likely an underestimation because it may be missed during physical examination or asymptomatic cases. The OMIM database of Mendelian abnormalities lists SMCP as a clinical finding in about 40 syndromes. Yet, isolated submucous cleft palate was found in $70 \%$ of

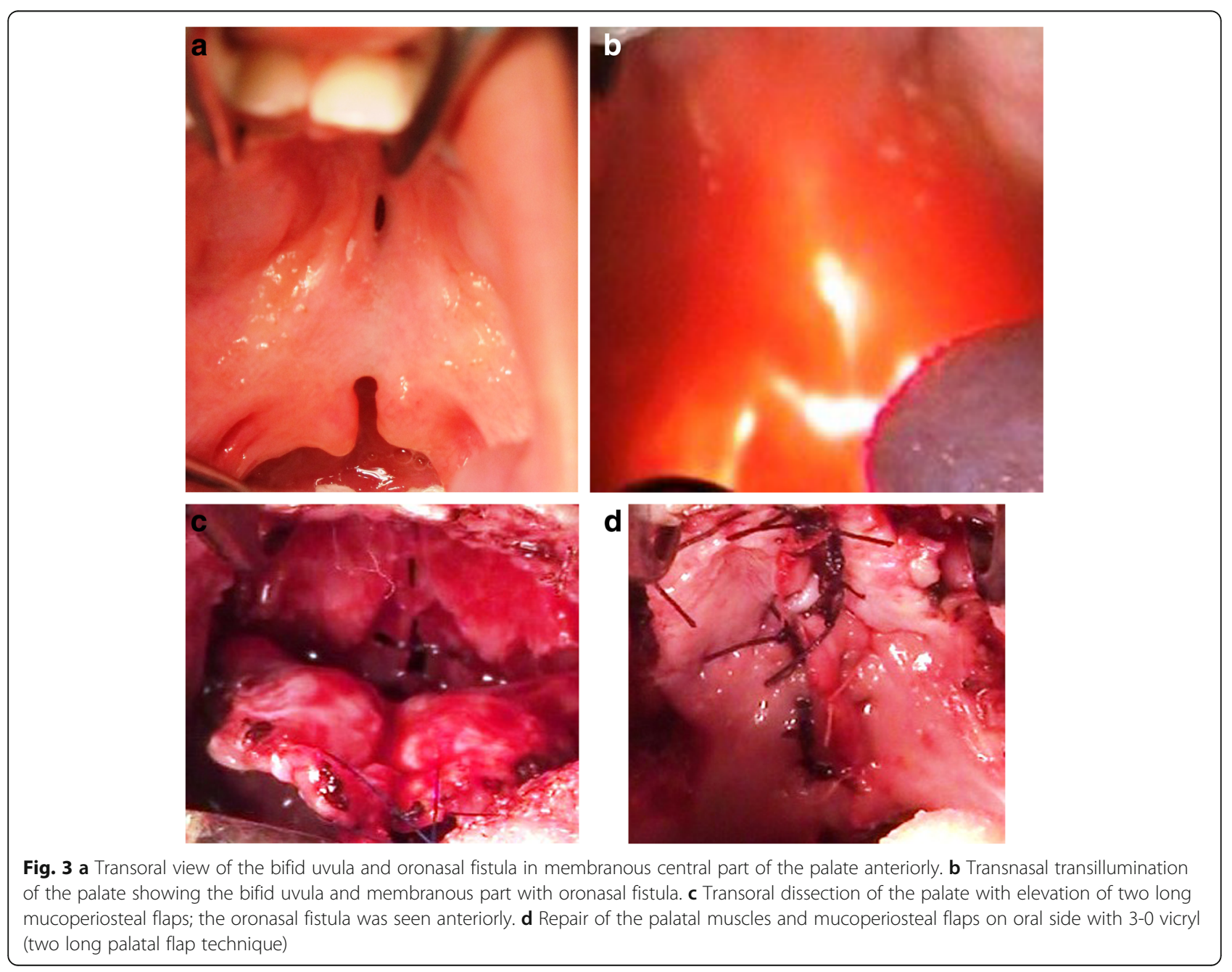



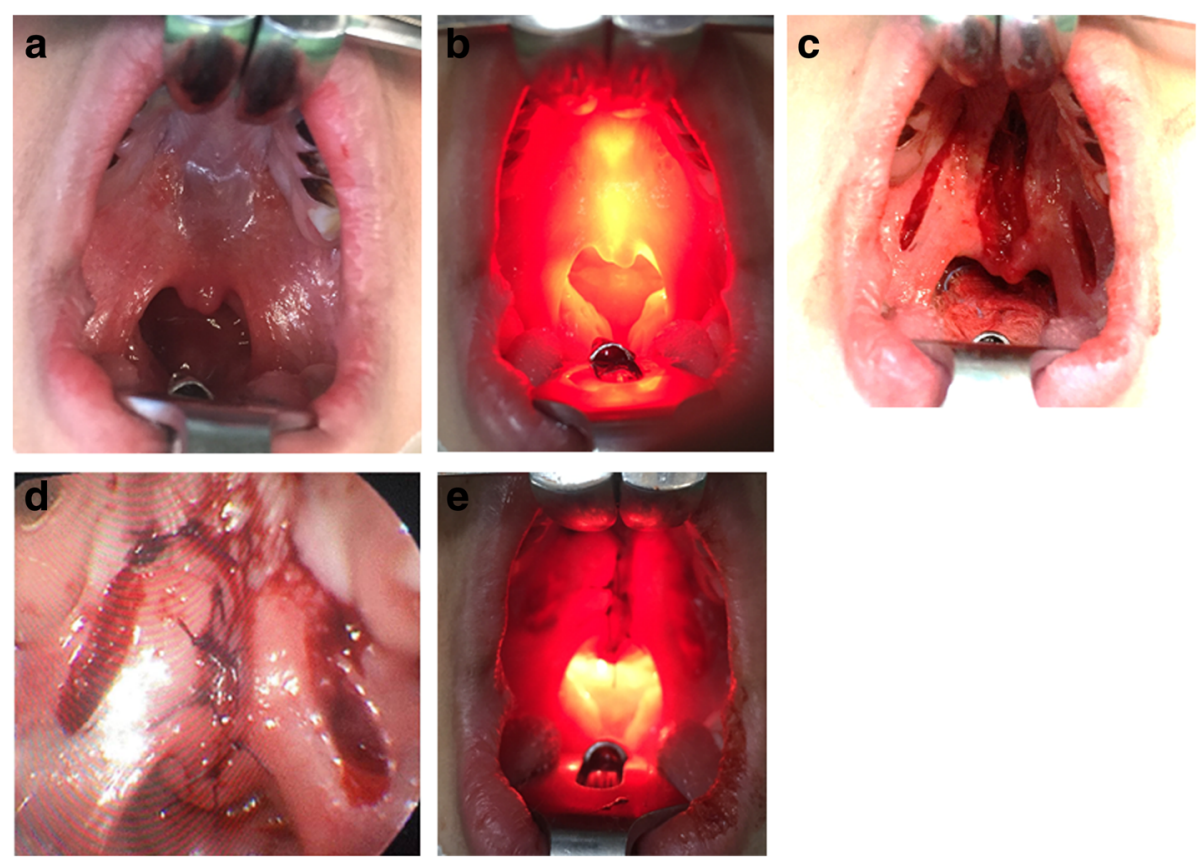

Fig. 4 a Transoral view of the bifid uvula and zona pellucida. $\mathbf{b}$ Transnasal transillumination of the palate showing the bifid uvula and membranous part of the palate extending to the bony part. c Transoral dissection of the central part of the palate (intersection of the palatal and nasal mucosa) with preservation of nasal mucosa showing the muscular part on both side of membranous palate with lateral release incisions (von Langenbeck technique). d Repair of the palatal muscles and mucoperiosteal flaps on the oral side with 3-0 vicryl. e Post-repair transnasal transillumination of the palate

Table 1 Demographic and clinical characteristics of patients ( $n$ =21)

\begin{tabular}{ll}
\hline Characteristics & Value \\
\hline Age (months) & 18.95 \\
Mean & 6.00 \\
Median & $(2.00-60.00)$ \\
Minimum-maximum & \\
Gender & $13(61.9 \%)$ \\
Male & $8(38.1 \%)$ \\
Female & \\
Presentation & $5(23.8 \%)$ \\
Hypernasality & $5(23.8 \%)$ \\
Delayed speech & $5(23.8 \%)$ \\
Diagnosed during repair of cleft lip & $3(14.3 \%)$ \\
Perforated palate with nasal escape of milk and food & $3(14.3 \%)$ \\
Feeding difficulties & $1(4.8 \%)$ \\
Otitis media & \\
Type of operations & $1(4.8 \%)$ \\
Simple repair without lateral release incisions & $2(9.6 \%)$ \\
Simple repair with lateral release incisions & $13(61.9 \%)$ \\
Two long palatal flaps & $5(23.8 \%)$ \\
Von Langenbeck & \\
\hline Age presented as mean medan, and minmum-maxmum and & \\
\hline
\end{tabular}

Age presented as mean, median, and minimum-maximum and other data as number (\%) cases [11]. Although the initiating causes in embryonic development is not known, the result is a disorganized array of atrophic myocytes and atypical fibrous tissue leading to absent tensor palatine aponeurosis [12]. The abnormalities is mostly idiopathic, although risk factors were detected as mother smoking and defects of transforming growth factor beta (TGFB)3, T-box transcription factor (TBX)22, and meningioma (MN)1 genes [13].

Detection of SMCP can be made on clinical finding, radiological imaging, intranasal endoscopic viewing, or intranasal palatal transillumination modality that are presenting in the current study. In spite the presence of different techniques to image and detect SMCP, little of these methods are routinely utilized by physicians prior to oropharyngeal surgery due to the limitation or the difficulties associated with them. In the past, different techniques were used. Olin (1960) points out that the bony cleft can be detected by palpation [14]; Van Riper wrote that submucous clefts of hard palate cannot be observed except by radiography [15]; Darley et al. suggested a submucous cleft might exist if speaker had a bifid uvula and speech which indicate poor velopharyngeal mechanism [16]. Cineradiographic analysis showed an abnormal pattern of swallowing [1]. Some diagnostic techniques, as video fluoroscopy or magnetic resonance imaging were effective but expensive, need many patient visits to set up appointments, and difficult to establish as 
preoperative SMCP screening evaluations. Ultrasound is quick and inexpensive but of restrict utilization in preoperative evaluation as it needs oropharyngeal surgeon to approach to an ultrasound apparatus with an intracavitary probe. Meanwhile, most otolaryngologists, oral, and craniofacial surgeons always utilize a flexible laryngoscopy before planned surgery to evaluate their cases. So, in this study, the authors found that addition of intranasal palatal transillumination to physical evaluation is good tool for SMCP diagnosis and its extent widthwise and lengthwise including bony palate involvement. Also, it can be used for screening due to its simplicity. The use of light transmission or penetration through the palate for assessment of the membranous part was attended through several ways. Massengill [17] described his adapted transillumination tool (with small light source at its tip) to measure light transmission through palate trans-nasally to be measured by photocells in palate on oral side that help in assessing palate thin part. Todd and Krueger [18] described in their cadaveric study the use of transmitted infrared light through palate to determine membranous cleft palate but no further application on living human patients was done. On the other hand, a similar technique to the one described in this study was reported in single SMCP case report by Caterson et al. [19] where membranous cleft palate diagnosis was made with help of trans-nasal or trans-oral transillumination test. However, this study includes 21 patients over a period of 15 years with different presentations. In our technique, stress was made on the use of adjustable-intensity light source that throw light equally over the palate without over illumination to determine extent of palate membranous area and to determine whether it is only of soft part or extending to bony part. Additionally, utilizing the transillumination in confirming SMCP diagnosis was done in 5 patients with cleft lip at repair time, $\mathrm{Qu}$ and Zhang [5] reported similar experience of high SMCP prevalence with isolated cleft lip which could be easily diagnosed by this simple technique of transnasal palatal transillumination. Our policy, if transillumination finding confirms SMCP, the parents can then be informed of VPI risk and need follow-up and early management to avoid irreversible speech abnormality or hearing problems.

All patients involved in this study with SMCP came symptomatic and suffers at diagnosis time; apart from 5 patients $(23.8 \%)$ who were diagnosed during cleft lip repair operations. Of our cases, $23.8 \%$ presented with hypernasality and $23.8 \%$ presented with delayed speech. The primary cause for most of SMCP children to brought to medical attention is abnormal speech accompanied with VPI, that happened in $5-10 \%$ of cases [20]. The speech symptoms of VPI include weak pressure consonants, hypernasality, audible nasal emission/ turbulence, and dysarthria. The speech problems caused by incomplete closure between oral and nasal cavity and insufficient pressure build up in oral cavity, hypernasality, and articulation defects develop [21]. With regard to speech, the first year of life is language acquisition basis with passive language development and active phoneme recognition of native language. Speaking of words begins at approximately 12 months age and recognizable speech becomes apparent at 18 months. By age of 6 years, the phonemic development is terminated and languagespecific speech characteristics are acquired. When abnormal speech is not treated early, articulation problems can become fixed in speech system and can remain persistent after surgical correction [22].

In addition to speech disorders, SMCP cases may have history of feeding difficulties and swallowing problems as nasal reflux and Eustachian tube dysfunction, especially in younger children, though there are conflicting reports about incidence of otitis media with effusion in SMCP patients [23]. In this study, $14.3 \%$ of cases (3 cases out of 21) presented with feeding difficulties and $4.8 \%$ ( 1 case out of 21 ) presented with otitis media. A review of over 80 SMCP cases showed that 22 out of 26 infants showed slowness to feed (taking more than 40 $\mathrm{min})$, together with nasal regurgitation for which no other causes were found [24].

All SMCP patients are not necessarily characterized by the classic triad of anatomical features described by $\mathrm{Cal}-$ nan [1]. Hence, a SMCP diagnosis may be overlooked in childhood, thereby predisposing the patient to complications, especially perforation. Although rare, perforations associated with SMCP are either acquired or congenital. In this study, $14.3 \%$ of our cases suffered from perforated palate with nasal escape of milk and food. Miroslav [25] reported 5 SMCP cases with perforation, including 4 with an isolated perforation and 1 with a cleft lip, whereas Weijerman and Heybroek [26] reported 1 case secondary to aphthous ulcers, and Cheng and Zhou [27] presented 4 congenital cases. Mehendale and Sommerlad [28] described 4 cases, including 2 with perforations due to membrane thinness occurring in neonatal period, 1 case secondary to denture, and 1 case of unknown etiology with fetal alcohol syndrome. Shah et al. [29] reported a 16-year-old patient with SMCP with a perforation along with microform lips and nose. Trauma is the most common etiological factor of perforation in acquired causes [1], whereas congenital perforation is mostly encountered with neonates and infants. The submucosal cleft area in congenital cases is histopathologically characterized by hypoplasia, fibrosis, and atrophied myocytes arranged randomly, resulting in fascicular disorganization. A palate with abnormal connective tissue and muscle is more sensitive to trauma and, therefore, has a greater risk of perforation, especially during feeding [30]. 
In this study, 1 patient (4.8\%) was operated with simple repair of cleft without lateral release incisions, while 2 patients $(9.6 \%)$ were operated with simple repair of cleft with lateral release incisions to minimize the tension on the repair, but the majority of the patients were repaired with long 2 palatal flaps technique (13 patients, 61.9\%) and von Langenbeck technique (5 patients, 23.8\%). There were no recorded complications in our cases after follow-up for 3 months. According to the extent of membranous part defective particularly membranous part width and involvement of bony palate where the need to use a technique with sufficient palatal flaps mobilization to close the wide membranous defect in order to avoid development of dehiscence or fistula.

An urge for elevated suspicion index for all general physicians, pediatricians and ear, nose, and throat specialists who are managing pre-school children when presenting with recurrent otitis media, nasal regurgitation, or speech problems to immediate consideration of SMCP diagnosis. Palate examination may show the characteristics mentioned above and leads to onward tertiary referral to regional cleft team for further investigation and therapy [6].

\section{Conclusions}

Submucous cleft palate is usually missed diagnosis that unrecognized till a patient had VPI symptoms, sometimes after oropharynx surgery. Palate transillumination is rapid, inexpensive, and simple incorporated method that can screen for undiagnosed SMCP and reduce occurrence of preventable SMCP complications in untreated cases. In this study, 21 cases were detected by intranasal transillumination method. The frequency of SMCP patients in our institute was 3.39\%. Further correlations between actual defect and lucent area need to be studied. Upon diagnosis, patients must be informed about complications accompanied with SMCP, and surgery must be performed as soon as possible.

\section{Abbreviations}

SMCP: Submucous cleft palate; MN1: Meningioma 1; TBX22: T-box transcription factor; TGFB3: Transforming growth factor beta 3; VPI: Velopharyngeal insufficiency

\section{Acknowledgements}

Not applicable.

\section{Authors' contributions}

All authors contributed equally in writing and revision of manuscript. YJ contributed specifically in patients' selection and operative technique. SM contributed in designing manuscript, selection cases, statistics analysis, and collecting data. AB contributed in design manuscript, selection cases, collecting data, and shared operative technique. MK shared in collecting data, statistical analysis, and shared operative technique. DJ shared in selection and examined cases, statistical analysis, and collecting reference. All authors have read and approved the manuscript for publications.

\section{Availability of data and materials}

The datasets used and/or analyzed during the current study are available from the corresponding author on reasonable request.

\section{Declarations}

Ethics approval and consent to participate

Not applicable and/not available. Written informed consent was obtained from a parent or legal guardian of participants under 16 years old.

\section{Consent for publication}

Not applicable.

\section{Competing interests}

The authors declared no potential conflicts of interest with respect to the research, authorship, and/or publication of this article.

\section{Author details}

${ }^{1}$ Pediatric and Plastic Surgery, Faculty of Medicine, King Abdulaziz University, P.O. Box 80215, Jeddah 21589, Saudi Arabia. ${ }^{2}$ Departments of Plastic Surgery, King Abdulaziz University Hospital, Jeddah, Saudi Arabia. ${ }^{3}$ Pediatric Surgery, Faculty of Medicine, King Abdulaziz University, Jeddah, Saudi Arabia.

${ }^{4}$ Departments of Pedodontics, King Abdulaziz University Hospital, Jeddah, Saudi Arabia.

Received: 11 February 2021 Accepted: 3 April 2021

Published online: 05 July 2021

\section{References}

1. Calnan J. Submucous cleft palate. Plast Reconstr Surg. 1954;14(1):84-5. https://doi.org/10.1097/00006534-195407000-00018.

2. Miguel HC, Genaro KF, Trindade IEK. Perceptual and instrumental assessment of velopharyngeal function in asymptomatic submucous cleft palate. Pró-Fono Rev Atualização Científica. 2007;19(1):105-12. https://doi. org/10.1590/50104-56872007000100012.

3. Kaplan EN. The occult submucous cleft palate. Cleft Palate J. 1975;12:356-68.

4. Sullivan SR, Vasudavan S, Marrinan EM, Mulliken JB. Submucous cleft palate and velopharyngeal insufficiency: comparison of speech outcomes using three operative techniques by one surgeon. Cleft Palate-Craniofac J. 2011; 48(5):561-70. https://doi.org/10.1597/09-127.

5. Qu E, Zhang X. EP15.28 Two cases of occult submucous cleft palate and literature review. Ultrasound Obstet Gynecol. 2019;54(S1):324. https://doi. org/10.1002/uog.21409.

6. Martin S, Slevin E, Hill C. The occult submucous cleft-improving detection by education. Ulster Med J. 2019;88:181-4.

7. Baek R-M, Kim B-K, Jeong JH, Ahn T, Park M, Han J. The effect of age at surgery and compensatory articulation on speech outcome in submucous cleft palate patients treated with double-opposing Z-plasty: a 10-year experience. J Plast Reconstr Aesthet Surg. 2017;70(5):646-52. https://doi. org/10.1016/j.bjps.2016.12.025.

8. Ha KM, Cleland H, Greensmith A, Chong D, Macgill K, Verhoeven A, et al. Submucous cleft palate: an often-missed diagnosis. J Craniofac Surg. 2013; 24(3):878-85. https://doi.org/10.1097/SCS.0b013e31827fef4b.

9. Martin S, Damkat-Thomas L, Foster P, Hayden C, O'Connor E, Hill C. The rise of the submucous cleft - A single centre review over 15 years, Annual Scientific Conference. Gateshead, Newcastle: Craniofacial Society of Great Britain and Ireland; 2017. p. 35.

10. Coran AG, Caldamone A, Adzick NS, Krummel TM, Laberge J-M, Shamberger R. Pediatric surgery E-book: 2nd volume, 7th edition. Philadelphia: Elsevier Health Sciences; 2012. p. 1603-11.

11. Reiter R, Brosch S, Goebel I, Ludwig KU, Pickhard A, Högel J, et al. A post GWAS association study of SNPs associated with cleft lip with or without cleft palate in submucous cleft palate. Am J Med Genet Part A. 2015;167(3): 670-3. https://doi.org/10.1002/ajmg.a.36891.

12. Oji T, Sakamoto Y, Ogata H, Tamada I, Kishi K. A 25-year review of cases with submucous cleft palate. Int J Pediatr Otorhinolaryngol. 2013;77(7): 1183-5. https://doi.org/10.1016/j.jporl.2013.04.033.

13. Osman AO, Yagi HI, Khalid OM. Pattern and ENT manifestations of cleft lip and palate in Sudanese children in Khartoum State, Sudan. Khartoum Med J. 2019;12:1603-11. 
14. Olin WH. Cleft lip and palate rehabilitation. Am J Orthod. 1966;52(2):126-44. https://doi.org/10.1016/0002-9416(66)90004-2.

15. Riper CV. Speech correction principles and methods. New York: Prentice Hall, Inc.; 1939

16. Darley FL, Spriestersbach DC, Johnson W. Diagnostic methods in speech pathology. New York: HarperCollins Publishers; 1978.

17. Massengill JRR. An objective technique for submucous cleft palate detection. Plast Reconstr Surg. 1966;37(4):355-9. https://doi.org/10.1097/ 00006534-196604000-00013.

18. Todd NW, Krueger BL. Minuscule submucous cleft palate: cadaver study. Ann Otol, Rhinol Laryngol. 1992;101(5):417-22. https://doi.org/10.1177/00034 8949210100508

19. Caterson E, Tsai DM, Cauley R, Dowdall JR, Tracy LE. Transillumination of the occult submucous cleft palate. J Craniofac Surg. 2014;25(6):2160-3. https:// doi.org/10.1097/SCS.0000000000001159.

20. Isotalo E, Pulkkinen J, Haapanen ML. Speech in 6-year-old children with submucous cleft palate. J Craniofac Surg. 2008;19(3):869-70. https://doi. org/10.1097/SCS.0b013e31816b1abd.

21. Pai BC, Hung Y-T, Wang RS, Lo L-J. Outcome of patients with complete unilateral cleft lip and palate: 20-year follow-up of a treatment protocol. Plast Reconstr Surg. 2019;143:359e-67e.

22. van Ommen S, Boll-Avetisyan N, Larraza S, Wellmann C, Bijeljac-Babic R, Höhle B, et al. Language-specific prosodic acquisition: a comparison of phrase boundary perception by French-and German-learning infants. J Mem Lang. 2020;112:104108. https://doi.org/10.1016/j.jml.2020.104108.

23. Qiu Q, Yuchen W, Chenghui J, Binbing W, Lili Q, Sheng L, et al. A preliminary dynamic investigation on velopharyngeal movements during blowing: a new approach for evaluation. J Craniofac Surg. 2020;31(2):464-7. https://doi.org/10.1097/SCS.0000000000006013.

24. Grover R, Barnett A, Rampazzo A, Papay F, Gharb BB. Outcomes of sphincter pharyngoplasty in the cleft population. J Craniofac Surg. 2018;29(4):908-13. https://doi.org/10.1097/SCS.0000000000004289.

25. FÁRA M. Congenital defects in the hard palate: observation of five cases Plast Reconstr Surg. 1971;48(1):44-7. https://doi.org/10.1097/00006534-1971 07000-00009.

26. Weijerman J, Heybroek G. Perforation in a case of submucous cleft palate due to an aphthous ulcer. Br J Oral Surg. 1972;10:217-9. https://doi.org/10.1 016/50007-117X(72)80040-4.

27. Cheng N, Zhou M. Congenital fistula of the palate. J Cranio-Maxillofac Surg. 1998;26(6):391-3. https://doi.org/10.1016/S1010-5182(98)80073-5.

28. Mehendale FV, Sommerlad BC. Submucous cleft palates presenting with a perforation. Cleft Palate-Craniofac J. 2003;40(2):203-6. https://doi.org/10.1 597/1545-1569_2003_040_0203_scppwa_2.0.co_2.

29. Shah S, Garg R, Uppal SK, Mittal RK. Sub mucous cleft palate with fenestration. Int J Appl Basic Med Res. 2014;4(Suppl 1):S56-7. https://doi. org/10.4103/2229-516X.140745.

30. Sales SAG, Santos ML, Machado RA, Dias VO, Nascimento JE, Swerts MSO, et al. Incidence of bifid uvula and its relationship to submucous cleft palate and a family history of oral cleft in the Brazilian population. Braz J Otorhinolaryngol. 2018;84(6):687-90. https://doi.org/10.1016/.jbjorl.2017.08. 004

\section{Publisher's Note}

Springer Nature remains neutral with regard to jurisdictional claims in published maps and institutional affiliations.

\section{Submit your manuscript to a SpringerOpen ${ }^{\circ}$ journal and benefit from:}

- Convenient online submission

- Rigorous peer review

- Open access: articles freely available online

- High visibility within the field

- Retaining the copyright to your article

Submit your next manuscript at $\boldsymbol{\nabla}$ springeropen.com 